\title{
Before the Creation of Time in Plato's Timaeus
}

\author{
Daniel Vázquez
}

\subsection{A Puzzle in Timaeus' Cosmogony}

In the Timaeus, Plato offers a detailed account of the beginning of the cosmos. In this account, a god creates an ordered, living, and intelligent cosmos by looking at a perfect model. Unlike the Christian god, who creates out of nothing, ${ }^{1}$ the god in the Timaeus creates from a pre-existing receptacle and some traces of fire, water, air, and earth, which move in a disorderly fashion (Timaeus $3 \mathrm{Oa2}-6$; $52 \mathrm{~d} 2-53 \mathrm{~b}_{7}$; 69a6-c5). Along with the cosmos, the god also creates time:

Now when the Father who had begotten the universe observed it set in motion and alive, a thing that had come to be as a shrine for the everlasting gods, he was well pleased, and in his delight he thought of making it more like its model still. So, as the model was itself an everlasting Living Thing, he set himself to bringing this universe to completion in such a way that it, too, would have that character to the extent that was possible. Now it was the Living Thing's nature to be eternal, but it isn't possible to bestow eternity fully upon anything that is begotten (gennètos). And so he began to think of creating ${ }^{2}$ a moving image of eternity: at the same time as he brought order to the universe, he would create an eternal image, moving according to number, of eternity remaining in unity. This number, of course, is what we now call 'time'.

Timaeus $37 \mathrm{c} 6-\mathrm{d} 7^{3}$

1 For the doctrine of creatio ex nihilo (creation out of nothing), its history, biblical support, and Christian and Jewish proponents, see Erasmus (2018) and Anderson and Bockmuehl (2018).

2 Plato uses the verb poieo,, "to produce," "to make" or "to create" (out of something).

3 Unless otherwise stated, translations are by Zeyl (2000) with minor modifications. The Greek

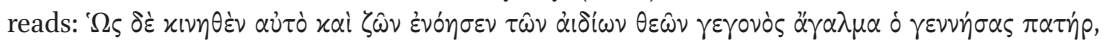

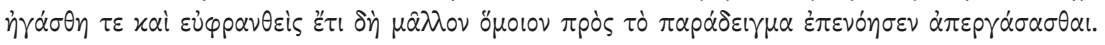

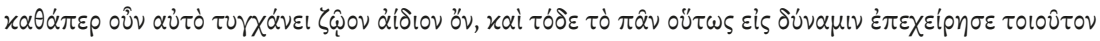

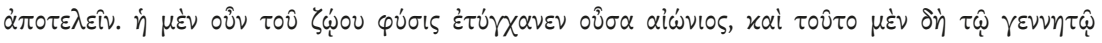

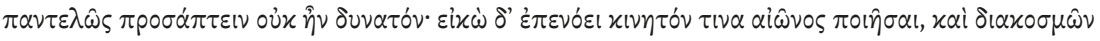

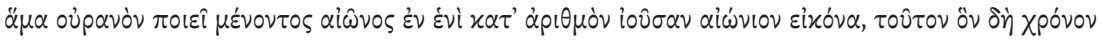

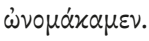


Despite what Plato writes in this passage, the Timaeus contains numerous references to the state of affairs before the creation of time. ${ }^{4}$ This gives rise to a famous puzzle: the creation of time seems inconsistent with the description of events that happened before its creation. Could something happen before time was created? Could time be created at all? What is the most charitable way to read the text?

Plato scholars react to this puzzle in two ways. Some (a) defend the consistency of the Timaeus' account, whereas others (b) acknowledge the inconsistency but minimize its importance. There are different ways to defend the first alternative. Many believe, for example, that the cosmogony (a1) is just a metaphor. They see no inconsistency because the creation of the cosmos and time is a metaphor that stands for relations of ontological dependence, not events in an actual timeline. ${ }^{5}$

Other scholars (a2) read the cosmogony as a literal and consistent description of facts but argue that the creation of time refers only to "cosmic time," a time inextricably linked to counting and measuring the regular movements of the celestial bodies. Obviously, before the creation of the celestial bodies and its movement, there is no cosmic time. But there is an implicit "pre-cosmic time," uncreated and unmeasurable. When Plato refers to events before the creation of time, he means things that happened before the celestial bodies were created; a time before people could count days or years. ${ }^{6}$

A more recent proposal understands the cosmogony as (a3) a counterfactual scenario. Here the description of a pre-cosmic stage of the universe is meant literally, but only as a thought experiment of what things would look like if we could — per impossibile — subtract god's actions from the picture. ${ }^{7}$ If the god were not permanently sustaining the cosmic order, then there would

4 See $T i .53 \mathrm{a} 2-\mathrm{b} 5,5^{2 \mathrm{~d}} 2-53 \mathrm{~b}_{7}, 69 \mathrm{a} 6-\mathrm{c} 5$.

5 Modern advocates of this reading are, among others, Taylor (1928), Cornford (1935), Cherniss (1944), Tarán (1971), Brisson (1998), and Fronterotta (2003).

6 The modern champion of this view is Vlastos (1939, 1964), but see also Hackforth (1959), Guthrie (1978, 300-304), and Mohr (1985). The dispute between a literal and a metaphorical reading goes back to Plato's immediate successors. See Aristotle, Ph. 251 bi7 and Cael. 279b33$28 \mathrm{oa}$. For more on this and the ancient discussion, see chapter 2 in this volume and footnote 11, below.

7 Let me be clear about the difference between a metaphorical and counterfactual reading. In a metaphorical reading, temporal terms stand in for ontological relations of dependency. In contrast, in a counterfactual reading, temporal terms are read literally. The description of the pre-cosmos is what would literally happen if only we could subtract god's action. 
be only a huge cosmic mess. Since the pre-cosmos and the cosmogony are not factual, the account's consistency is preserved. ${ }^{8}$

Alternatively, some acknowledge that there is inconsistency in Timaeus' cosmogony but downplay its importance (bi). ${ }^{9}$ We find some support for this last view at Timaeus 29c4- $\mathrm{d}_{3}$, where Timaeus warns us that some inconsistencies in his account are unavoidable:

Don't be surprised then, Socrates, if it turns out repeatedly that we won't be able to produce accounts on a great many subjects—on gods or the coming to be of the universe - that are completely and perfectly consistent and accurate. Instead, if we can come up with accounts no less likely than any, we ought to be content, keeping in mind that both I, the speaker, and you, the judges, are only human. So, we should accept the likely tale on these matters. It behooves us not to look for anything beyond this. ${ }^{10}$

Each of these alternatives has serious consequences for our reading of Timaeus' cosmology. The decision determines, for example, whether the cosmos has always existed or had a punctual beginning. If the cosmogony is a metaphor or a counterfactual scenario, then the cosmos has always existed. Otherwise, it had a beginning. Our interpretation of the cosmogony also affects the way we conceive of divine causation. If it is a description of facts, then the god is an active agent that produces the cosmos. But if the cosmogony is a counterfactual, the god could instead be a continuous, sustaining cause. If we assume the creation is metaphorical, the causation at play could be only formal. Ultimately, the very nature of time is at stake. Depending on our reading, either time is everlasting and without limits at both ends, or it has a beginning and is unlimited only toward the future. ${ }^{11}$

The clearest advocates of this proposal are Carone 2004 and chapter 3 in this volume. See also Burnyeat 2005, 163. Brisson and Fronterotta sometimes refer to the cosmogony as some sort of thought experiment, even if they endorse a metaphorical reading of the Timaeus at a more general level. See Brisson 1998, 297 and Fronterotta 2010. For discussion and a different alternative, see Johansen 2004, 89-91.

9 See, for example, Sedley 2007, 98-110.

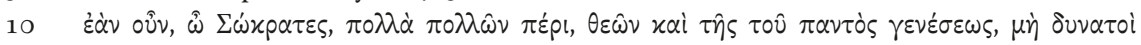

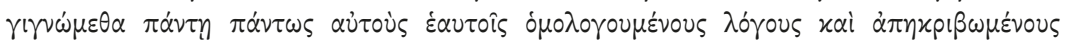

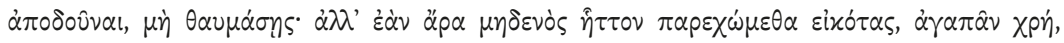

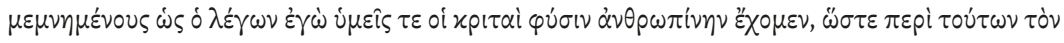

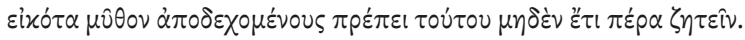

11 For even more replies to this puzzle, see Sorabji (1988, ch. 17) and Baltes (1996). In antiquity, Aristotle, Plutarch, Atticus, the Epicureans and probably Polemo, Antiochus, Cicero, Severus, Harpocriton, and other Platonists read the cosmogony in a literal way; see Sedley 
In this chapter, I defend reading Timaeus' creation of the cosmos and time as a consistent, literal, and factual account (i.e., a new [a2] reading). ${ }^{12}$ To this end, I shall answer the main objections scholars raise against this type of reading. However, instead of assuming or positing some sort of pre-cosmic time, like previous (a2) readings, I argue that in the Timaeus, Plato puts a lot of effort into showing that time presupposes but is not identified with a mere succession of events (i.e., an unbounded sequence where events can be placed in before, after, and simultaneous relations).

My main purpose, however, is not to persuade everybody that my reading of the text is the correct one-after all, scholars tend to be stubborn on this issue. But I do wish to clarify the assumptions under which it becomes a sensible and fruitful interpretation. In what follows, I will first assess the state of the debate and the most common objections to the traditional interpretations. Then, I will discuss some of my exegetical principles and articulate my reading of the Timaean cosmogony and time. Finally, I will evaluate whether my reading delivers on what I have promised.

\subsection{Assessment of the Contemporary Debate}

Scholars have offered strong objections to both a metaphorical cosmogony (i.e., a1) and the possibility of a consistent and factual creation (i.e., a2). The main problem with the first one is that-despite its illustrious pedigree and widespread acceptance-some passages seem to rule it out. For example, scholars often quote Timaeus $28 \mathrm{~b} 2-\mathrm{c}_{5}$ as evidence against a metaphorical reading:

$(2007,107)$. The Stoics also seem to have developed their cosmology from a literal reading of Plato. See Sedley 2002. However, the metaphorical interpretation was the most widespread reading of the text in the Academy and Neoplatonic circles. Supporters of this reading include Speusippus, Xenocrates, Crantor, and Proclus. See Guthrie $(1978,303)$ and Carone (2004, n. 2). Finally, in some passages, Simplicius seems to suggest that the cosmogony is a counterfactual. See In Cael. 303.34-304.12.

12 Notice that a description of facts does not need to be perfectly accurate. It is committed to the existence of certain facts, but as a description, it only needs to be appropriate or reasonable given the available evidence, human limitations, or its announced purpose. For example, if a worker narrates an incident that happened at work, she might not get all the details right, but as far as she presents it as an incident, she commits herself to its factuality. She is claiming that what she describes really happened, even if there are some holes in her account. In that sense, a factual interpretation is compatible with the status of the speech as an eikōs mythos. For more on this, see footnote 22 below; for discussion, see chapters 2 and 3 in this volume. 
Now as to the whole universe or world order [kosmos] —let's just call it by whatever name is most acceptable in a given context-there is a question we need to consider first. This is the sort of question one should begin with in inquiring into any subject. Has it always existed? Was there no origin from which it came to be? Or did it come to be and take its start from some origin? It has come to be. For it is both visible and tangible and it has a body — and all things of that kind are perceptible. And, as we have shown, ${ }^{13}$ perceptible things are grasped by opinion, which involves sense perception. As such, they are things that come to be, things that are begotten. Further, we maintain that, necessarily, that which comes to be must come to be by the agency of some cause. Now to find the maker and father of this universe [to pan] is hard enough, and even if I succeeded, to declare him to everyone is impossible. ${ }^{14}$

In this passage, Timaeus seems to clearly state that the cosmos had a beginning. Scholars point out, for example, the contrast between what "always existed" and the cosmos' status as something that "has come to be" (see also Timaeus 27( $4-5$ ), and the need of the agency of some cause to bring the cosmos into existence. ${ }^{15}$

Scholars also raise strong objections against reading the cosmogony as a consistent description of facts (i.e., a2). Four objections stand out. The first one argues that (i) the text rules out a "pre-cosmic time" (see Timaeus 37e4-38a8). A second objection contends that (ii) a factual cosmogony is incompatible

13 See Ti. $27 \mathrm{~d} 5^{-28 \mathrm{a} 4 .}$

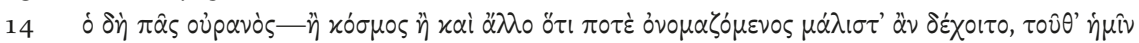

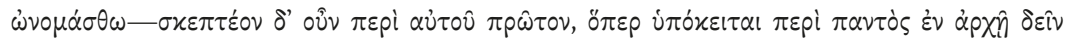

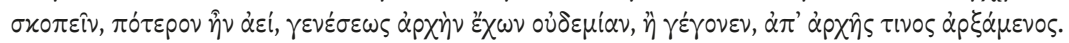

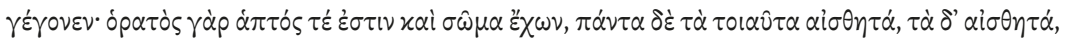

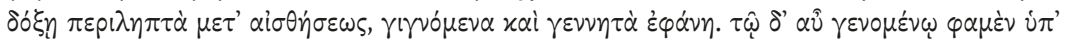

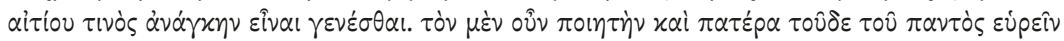

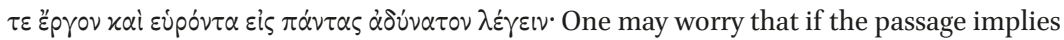
a punctual beginning, the argument does not work. It would illicitly conclude that the cosmos came to be from the fact that we can perceive becoming in the sense of constant

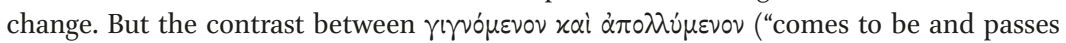
away") at Ti. 28a3 indicates that Timaeus refers here not only to constant change but also to the fact that perceptible things come to be and pass away. This is also emphasized by

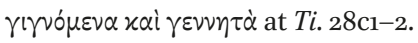

15 Many of the difficulties with the metaphorical reading were already found in Alexander of Aphrodisias (ap. Philoponus, De aet. mundi 214, 10-20; 215, 4216, 6; and Simpl., In Cael. 297.26-298.16). See Sorabji 1988, 275. For other strong objections against the metaphorical reading see Vlastos 1939, 1964; Skemp 1942, 111; Hackforth 1959; Sorabji 1988, ch. 17; Johansen 2004, 48-68; Sedley 2007, 98-110. 
with the immutable relation the god maintains with the world (see Timaeus 42e5-6; see also Republic 381c1-10). Some people also point out that (iii) this interpretation contradicts important Platonic doctrines found elsewhere. For example, the claims that souls are not generated and are the cause of all motion (Phaedrus 245c5-246a2; Laws x, 892a1-b2), or that generation and destruction are a pair that go hand in hand (Republic 546a2). Finally, some worry that (iv) a literal cosmogony cannot say why the world was created at the specific moment it was created and not sooner or later. ${ }^{16}$

Although many people still assume or support these two interpretations (a1 or a2), the discussion is at a standstill. Scholars often rephrase the same objections and offer the same passages for choosing one interpretation over the other. ${ }^{17}$ At this point, you might think that the two remaining optionsunderstanding the cosmogony as a counterfactual scenario (a3) or concluding that the inconsistency is not so serious after all (bi) - become the most plausible solutions to our puzzle.

However, when it is closely scrutinized, I find serious difficulties with the suggestion that the cosmogony could be a counterfactual scenario (a3). I see three main reasons to reject it. The most obvious one is that the textual support is weak. The passage often mentioned as hinting at a counterfactual cosmogony is found in the description of the pre-cosmos at Timaeus 53a7-b5:

Indeed, it is a fact that before this took place the four kinds all lacked proportion and measure, and at the time the ordering of the universe was undertaken, fire, water, earth and air initially possessed certain traces of what they are now. They were indeed in the condition one would expect

16 See Cicero, Nat. D. I 18-23 (LS13G); Carone 2004; Johansen 2004, 9o. For other objections, see Tarán 1971; Baltes 1996; Dillon 1997.

17 One exception is Johansen (2004, 90-91) who—crediting Myles Burnyeat for the ideaoffers a way to avoid both a metaphorical reading and most of the objections raised against reading the text as a consistent factual account. He suggests that the cosmogony is perpetually occurring as the world tends to chaos, and the god continuously intervenes to fix it. The pre-cosmos could be a disorder that either happens occasionally or is just potentially prior to the Demiurge's intervention. But just as in the metaphorical reading, this view struggles to explain the use of the perfect tense gegonen ("has come to be") at Ti. 28b7. If the creation of the cosmos is a recurrent or continuous event, why did Plato not use the imperfect instead of the perfect tense? The same objection applies to Carone (2004), who thinks that the perfect tense could cover the meaning of the imperfect. Moreover, Ti. 31b, 37d, and 38b6-c6 discard the possibility that the disorder occasionally happens after the cosmos has already come to be. If the pre-cosmos only occurs potentially but counterfactually, then Johansen's view collapses into (a3), in which case, see the objections above. 
for anything whenever (hotan) the god is absent from it. So, finding them in this natural condition, the first thing the god then did was to give them their distinctive shapes, using forms and numbers. ${ }^{18}$

The pre-cosmic state occurs whenever the god is absent from the things in the cosmos. Now, if one adds the thought that god would never abandon the world, since that would compromise his immutable relationship with it, then a counterfactual reading of this passage becomes more appealing. However, the text never really suggests that the pre-cosmos may not have happened. It indicates that it happened and could in principle happen again-although it would not. Moreover, Critias 106a3-4 seems to completely discard this possibility: "Now I offer my prayer to that god [i.e., the cosmos] who came to be long ago in reality, but who has just now been created in my words" [ $\tau \hat{\omega} \delta \dot{\varepsilon}$

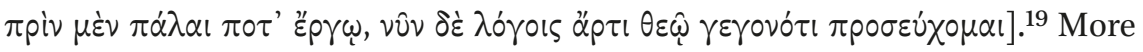
importantly, even if Timaeus 53a8-b4 allows a counterfactual reading of the cosmogony, it seems, then, that we should not only suppose that there is no cosmos but that there is no time either. Timaeus $53 b_{3}-4$ suggests god's complete absence, and both time and the cosmos seem inextricably linked..$^{20}$ But if that is so, either the description of the pre-cosmos is metaphorical, or we have to assume there is some type of pre-cosmic time, which are prospects this kind of reading was supposedly trying to avoid. Finally, in the counterfactual interpretation of the cosmogony, the god seems to collapse into the World Soul. Although some scholars are ready to accept this consequence, it seems to rely on assuming an even more widely metaphorical reading of the Timaeus.

Should we then settle for the interpretation that accepts the inconsistency but minimizes its importance (bi)? One could still complain that even if Timaeus recognizes that inconsistencies will remain, claiming some things happen before the creation of time cannot be covered by this because it is not a minor slip. On the contrary, it is an inconsistency that threatens to collapse the whole cosmological account. Accepting this inconsistency makes the Timaeus' cosmology not a likely story but an impossible one. Thus, the real

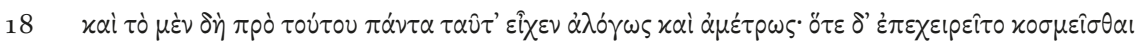

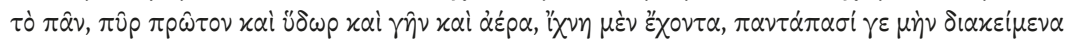

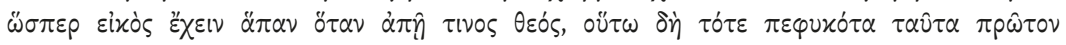

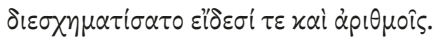

19 Translated by Diskin Clay in Cooper and Hutchinson 1997. The authenticity of the Critias has recently been doubted by Rashed and Auffret (2017) but this has been thoroughly debunked by Tarrant (2019). For a different reading of this passage, see chapter 3.2 in this volume.

See Ti. $38 \mathrm{~b} 6-7$, quoted below. 
question is whether we can offer something better than biting the bullet and accepting the inconsistency.

\subsection{Cosmogony without Inconsistency}

In this section, I first explain the methodological considerations and assumptions that make my interpretation a plausible solution to the puzzle of the creation of time. Then, I offer my proposal and show how it avoids objections previous scholars have raised against similar interpretations.

\subsubsection{Methodology}

Some exegetical principles operate in the background of discussions about Timaeus' cosmogony. Interpretations often originate from different starting points and assumptions, and when these are not made explicit, the discussion gets muddled. To avoid this risk, let me briefly state five exegetical principles I presuppose in my interpretation. Some of them sound obvious and commonsensical but will become crucial to the resistance of certain objections and explain the appeal of a factual reading of the cosmogony.

My first exegetical principle is that (EP1) for any account, coherence implies and is better than consistency, which, in turn, is preferable to inconsistency. ${ }^{21}$ Second, I think (EP2) that all things being equal, the more explanatory an interpretation, the better (i.e., if an interpretation leaves certain elements unexplained, that counts as a disadvantage). Furthermore, I assume (EP3) a literal reading of a text is preferable to a metaphorical one unless we find clear evidence of a frame setting the metaphor, or the literal meaning of the passage is unintelligible (internally and in conjunction with the rest of the text). ${ }^{22}$ A fourth principle establishes the following hierarchy: (EP4) having textual evidence for $X$ is preferable to simply inferring $X$ from the main text. But inferences from the main text are preferable to referring to quotes from other texts. All this is better than providing missing premises that cannot be inferred but

21 I use "consistent account" to refer to an account without contradictions, whereas I use "coherent account" to mean a consistent account whose parts fit together to form a whole.

22 The status of Timaeus' speech has been widely discussed and I will not examine this issue here. However, it should suffice to say that the phrases eikōs logos and eikōs mythos are not clear evidence for a metaphorical reading. If I offer a likely or probable story of my longforgotten childhood, I do not need to resort to metaphors. I can offer a literal account (I mean what I am saying) that aims to be factual (I am not embellishing anything nor taking any poetical license). For discussion see Johansen 2004, ch. 3; Burnyeat 2005; Betegh 2010. 
are compatible with the textual evidence. That is better still than resorting to claims with no textual support that are incompatible, contradictory, or, worse, that require emending the main text on contentious philosophical grounds alone. Finally, I assume that $\left(\mathrm{EP}_{5}\right)$ internal coherence and consistency of a text is more important than coherence and consistency between different texts from the same author (or with later interpreters), even when the latter is still desirable if allowed by the other exegetical principles.

According to this, whenever possible, we should prefer a literal, coherent reading, based on textual evidence and inferences directly deriving from it. Furthermore, we should give priority to the internal coherence of a text and the explanatory power of a given interpretation. Finally, the overall purpose is to uphold these principles together, avoiding as far as possible the fulfilment of one of them at the expense of another (e.g., achieving coherence by forcing a metaphorical reading that has not enough textual support).

\subsubsection{Defense of a Consistent and Factual Cosmogony \\ 4.3.2.1 Time Means Cosmic Time}

I agree with previous defenses of a factual cosmogony (i.e., a2) regarding claims that in the Timaeus, chronos ("time") refers only to cosmic time. That is to say that time in the Timaeus is created, measurable, regular, dependent on recurring motion, and linked to the life and movement of the celestial bodies. ${ }^{23}$ Consider for example Timaeus 37e1-38a8:

For before the heavens came to be, there were no days or nights, no months or years. But now, at the same time as he framed the heavens, he devised their coming to be. These all are parts of time, and was and will be are forms of time that have come to be. Such notions we unthinkingly but incorrectly apply to everlasting being. For we say that it was and is and will be, but according to the true account only is is appropriately said of it. Was and will be are properly said about the becoming that passes in time, for these two are motions. But that which is always changeless and motionless cannot become either older or younger in the course of time-it neither ever became so, nor is it now such that it has become so, nor will it ever be so in the future. And all in all, none of the characteristics that becoming has bestowed upon the things that are borne about in the realm of perception are appropriate to it. These, rather, are forms 
of time that have come to be-time that imitates eternity and circles according to number. ${ }^{24}$

Before the creation of time, there were no measurable units of time (days, months, years). A little later, at Timaeus 38b6-c6, Timaeus explains that the planets are brought into being with the express purpose of producing time, setting limits and numbers to it: ${ }^{25}$

Time, then, came to be together with the universe so that just as they were begotten together, they might also be undone together, should there ever be an undoing of them. And it came to be after the model of that which is sempiternal, so that it might be as much like its model as possible. For the model is something that has being for all eternity, while it, on the other hand, has been born (gegonōs), is, and shall be for all time, forevermore. Such was the reason, then, such the god's design for the coming to be of time, that he brought into being the Sun, the Moon and five other stars, for the begetting of time. These are called 'wanderers,' and they came to be in order to set limits to and stand guard over the numbers of time. ${ }^{26}$

Time - as understood by Timaeus - has come to be, could be stopped, and is produced by or is the circular and countable movements of the planets. ${ }^{27} \mathrm{In}$ other words, time here only means the countable movements of the celestial clock, which has been set into motion by the Demiurge. There is no evidence

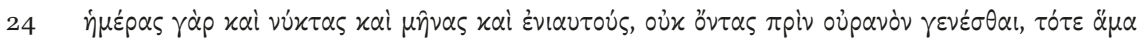

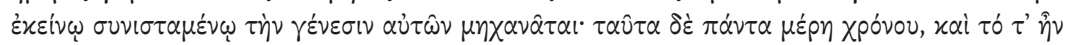

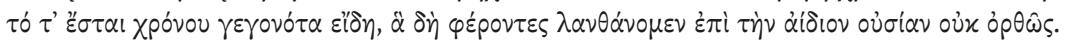

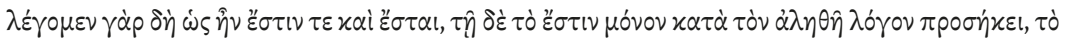

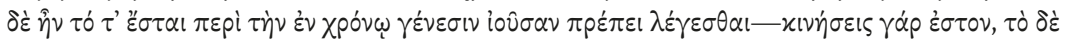

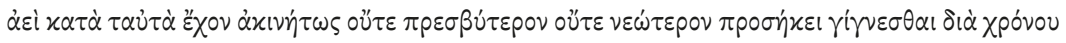

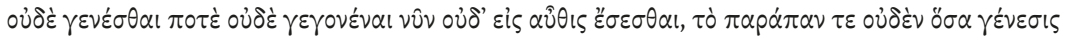

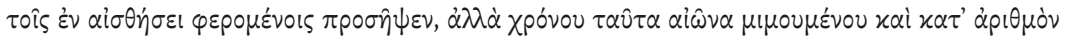

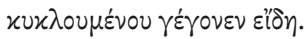

25 See also Ti. 38e3-39a3.

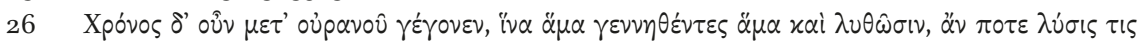

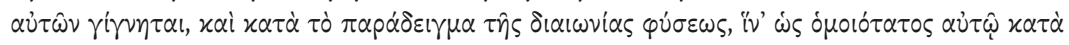

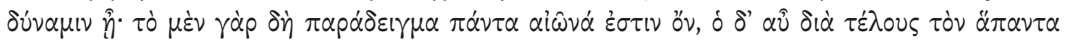

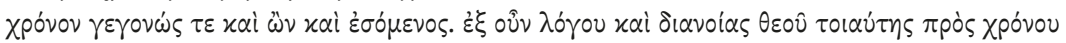

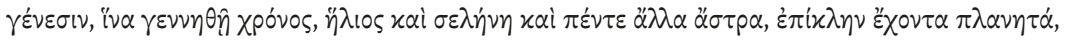

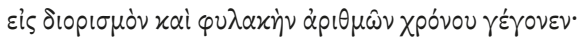

27 For discussion regarding the ontological status of time in the Timaeus, see Cornford ([1935] 1997, 97-116), Mohr (1985, ch. 2; 1986), and chapter 5 in this volume. 
to suggest that Timaeus understands time (i.e., chronos) as an absolute notion unrelated to planetary movements. Time in the Timaeus only means intra-cosmic, created time. ${ }^{28}$

\subsubsection{Pre-Cosmos without Cosmic Time}

If the previous point is correct, we can explain the pre-cosmic stage without cosmic time. The only features we need are the notions of before, after, simultaneity, and succession. Cosmic time presupposes all these features, of course, but they are independent of it. Consider the following case: imagine I find my son's room in a complete mess because he has been playing all day. I enter the room and I tell him that he has ten minutes to tidy up and that I am setting a timer. Now I can tell with precision at what time he put each toy in its place, I can measure how fast he is doing it, and so on. Yet, I can still meaningfully refer to the room's state before I set the clock and offer a broad account of what things looked like, even if I cannot place any of the events in a determinate time. Also notice that in the dialogue, Timaeus never claims that the god creates the basic temporal features required to make sense of the pre-cosmos. On the contrary, the cosmogony presupposes them as given. ${ }^{29}$

Some scholars resist this interpretation. Von Leyden $(1964,43)$, for example, thinks that the cosmogony does not imply time has a beginning because the god creates temporality as a whole, not the opening moment of the time series. This seems to be suggested, for instance, by $37 \mathrm{e} 4$, where Timaeus says

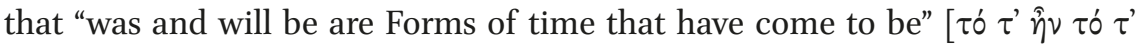

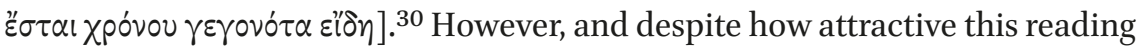
might sound, the "creation" of temporality turns out either to be a metaphor or to presuppose a second timeline, in which case the objections against (a1) or (a2) would still apply, respectively. More importantly, the context of $37 \mathrm{e} 4$ makes it clear that Timaeus already presupposes the circular movement of the celestial bodies that allow counting and measuring. The text refers to kinds of time where events and things are stable enough to be measured and numerically determined. In the pre-cosmos this is not the case. The traces' instability and ephemeral ontological status make this impossible. Measurable, stable, identifiable tensed existence only occurs inside the created cosmos and inside

28 It is unclear, however, whether this applies to other Platonic dialogues. In the Statesman myth, for example, the god changes the direction of the rotation of the celestial bodies, and although this intervention reverses ageing and generation, does not seem to reverse time. For the Statesman myth, see chapter 1 in this volume.

29 See, for example, prin at Ti. 37e2, 52d 4, 53a7; tote at Ti. 53a2; pro at Ti. $53 \mathrm{a} 8$.

$30 \quad$ For more on this passage, see chapter $5 \cdot 3$. 
cosmic time. But it does not follow that all possible references to "before" are like this. This is confirmed just a couple of lines later at 38a1-2: "Was and will be are properly said about the becoming that passes in time, for these two are

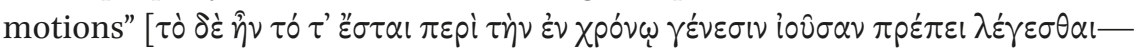

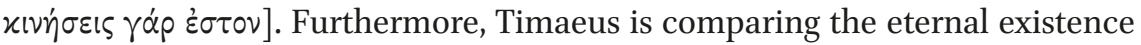
of the paradigm with the created cosmos. The pre-cosmic stage is simply ignored in this passage. ${ }^{31}$

Another reason for thinking that the cosmogony presupposes the basic features of before, after, and simultaneity independent from cosmic time is that the pre-cosmos is not in absolute chaos. Its interactions are just nonprogressive. ${ }^{32}$ We can identify one type of movement (rectilinear), there is a like-to-like sorting principle, and there are traces that can be generally located and differentiated. A broad sequence of events can be described, even if the duration of these stages or events cannot be properly determined with temporal units (i.e., days, months, and years): ${ }^{33}$

There are being, space, and becoming, three distinct things which existed even before the universe came to be. Now as the wetnurse of becoming turns watery and fiery and receives the character of earth and air, and as it acquires all the properties that come with these characters, it takes on a variety of visible aspects, but because it is filled with powers that are neither similar nor evenly balanced, no part of it is in balance. It sways irregularly in every direction as it is shaken by those things, and being set in motion it in turn shakes them. And as they are moved, they drift continually, some in one direction and others in others, separating from one another. They are winnowed out, as it were, like grain that is sifted by winnowing sieves or other such implements. They are carried off and settle down, the dense and heavy ones in one direction, and the rare and light ones to another place. That is how at that time the four kinds were being shaken by the receiver, which was itself agitating like a shaking machine, separating the kinds most unlike each other furthest apart and pushing those most like each other closest together into the same region. This, of course, explains how these different kinds came to occupy different

31 On this topic, see also Mohr 1985, 64-66.

32 See Gregory 2008, xliii-xlv.

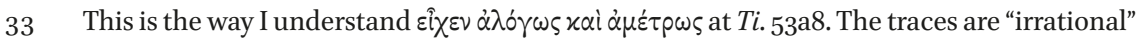
in the sense that they cannot be determined, like irrational numbers. 
regions of space, even before the universe was set in order and constituted from them at its coming to be.

Timaeus $5^{2 \mathrm{~d}} 3^{-}-53^{3} 7^{34}$

The events in the pre-cosmos can be ordered according to before, after, and simultaneity without implying they could be counted or measured, or that there is any recurring regular motion or celestial body. All these things, however, are essential features of time as described by Timaeus. In other words, in Timaeus' account, time presupposes but cannot be identified with the features derived from a simple succession of events. ${ }^{35}$ There is no need to assume that succession of events is another type of time or a pre-cosmic time. What the text suggests is that without number, regular movement, and celestial bodies, a succession of events and the basic features this implies (before, after, simultaneity) — which are fundamental—are not what people call time.

Confusion arises if we start from the presupposition that time in the Timaeus is an absolute notion, independent from events. But that is to impose a Newtonian conception of time on a text that repeatedly insists this is not the case. Think about it in this way. When we find any temporal notion in a narrative, we immediately tend to assume it happens in time. But the Timaeus

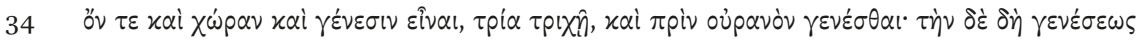

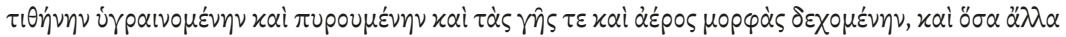

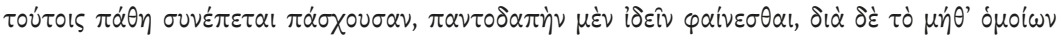

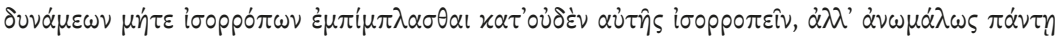

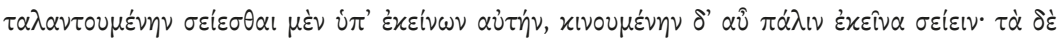

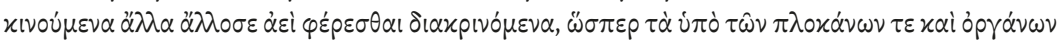

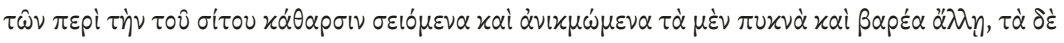

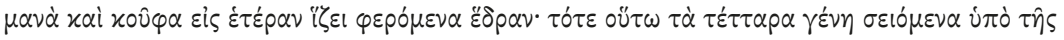

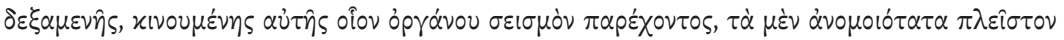

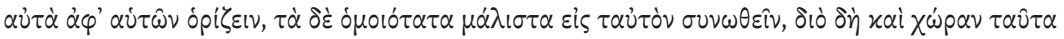

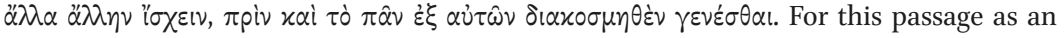
implicit critique of Democritus, Leucippus, and Empedocles, see Cornford (1935, 198203), and Gregory (2001, 22-26; 2007, 144).

35 Skemp $(1942,111)$ makes a similar point but, instead of a succession of events, talks about duration: "One cannot dismiss the doctrine of a literal creation of the formed universe in time by quoting the saying that time came into being with the universe. This does not imply that there was no duration before the creation of the formed universe. Xpóvos is the image of eternity moving according to number: it is the $\pi \dot{\varepsilon} \rho \alpha \varsigma$ imposed upon an $\ddot{\pi} \pi \varepsilon i p o v$ of duration." See also Hackforth 1959, 22. But Skemp's duration may face the same objection as Vlastos' precosmic time. It is a notion that is not in the text and has to be posited by the reader. But this can be seen as imposing a unified and anachronistic concept or distinction which is absent in the text. What I argue, instead, is only that before the creation of time we have a succession of events that cannot be counted or measured but that it is described with the vocabulary of the relations of before, after, and simultaneity. Given the way Timaeus defines time, the precosmic sequence of events cannot be said to happen in time. 
operates with a restricted notion of time that sets a higher threshold. For a sequence of events to occur in time as defined by Timaeus, we need more than simple relations of before, after, and simultaneity.

\subsubsection{God's Activity Is Always the Same If Correctly Specified}

The god's proper activity is being wholly good. Specified as such, it is true before, during, and after the creation of the cosmos. It is not difficult to see why the god is good during the creation of the cosmos since he is performing a good deed. In fact, he creates and orders because he is good, not the other way around: ${ }^{36}$

Very well then. Now why did he who framed this whole universe of becoming frame it? Let us state the reason why: He was good, and one who is good can never become jealous of anything. And so, being free of jealousy, he wanted everything to become as much like himself as was possible. In fact, men of wisdom will tell you (and you couldn't do better than to accept their claim) that this, more than anything else, was the most preeminent reason for the origin of the world's coming to be. The god wanted everything to be good and nothing to be bad so far as that was possible, and so he took over all that was visible — not at rest but in discordant and disorderly motion - and brought it from a state of disorder to one of order, because he believed that order was in every way better than disorder. Now it wasn't permitted (nor is it now) that one who is supremely good should do anything but what is best. Accordingly, the god reasoned and concluded that in the realm of things naturally visible no unintelligent thing could as a whole be better than anything which does possess intelligence as a whole, and he further concluded that it is impossible for anything to come to possess intelligence apart from soul. ${ }^{37}$ Guided by this reasoning, he put intelligence in soul, and soul in body, and so he constructed the universe. He wanted to produce a piece of work that would be as excellent and supreme as its nature would allow. This, then, in keeping with our likely account, is how we must say divine providence brought our world into being as a truly living thing, endowed with soul and intelligence.

Timaeus $29 \mathrm{~d} 7-3$ oc1 $^{38}$

36 A point also made by Harte (2002, 221) who reminds us of Euthphr. 10a2-3.

37 See Ti. 46d $5-6$.

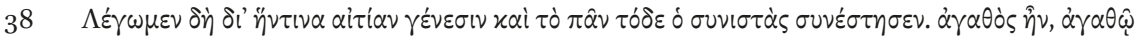

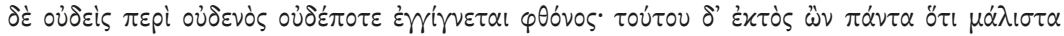

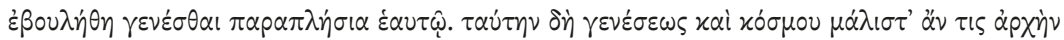


Consider now the situation after the creation of the cosmos. At this point, the god's activity is contemplating his creation and abstaining from destroying what he created. ${ }^{39}$ The immortality of the cosmos and time depends on the god's active and continuous decision not to destroy the cosmos. That is what it means to be good once the cosmos has been created.

Some scholars argue that a literal reading would imply that after the creation, the god undergoes some change. The passage that seems to suggest this

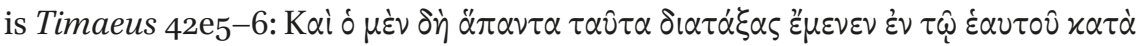

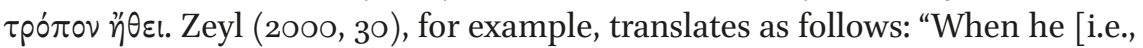
the god] had finished assigning all these tasks, he proceeded to abide at rest in his own customary nature." This seems to imply that the god's activity stops. However, this is incorrect because — as Cornford $([1935] 1997,147)$ has pointed out-emenen does not mean rest or cessation of activity. Some other translations suggest that the god changed because he returned to his habitual state. ${ }^{40}$ But again, the text does not imply a return to a previous state but only that he remained in character. In this regard, Cornford's translation is more precise: "When he had made all these dispositions, he continued to abide by the wont of his own nature" (my emphasis). Then, the text only amounts to saying that after the creation, the god was still good.

The real problem, you may think, is explaining god's activities before the creation of the cosmos. Although Timaeus' account does not say anything about this, there are various possible options compatible with the god's goodness. For example, the god could have been looking at the Forms. After all, Forms are the proper object of his intelligence. ${ }^{41}$ Or, perhaps he was busy with previous, unsuccessful attempts at creating the best possible cosmos. Here, it is

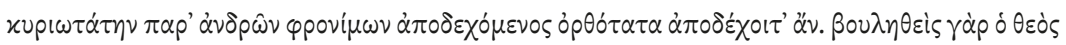

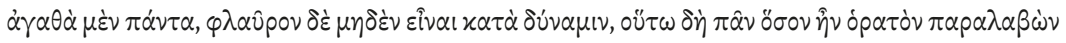

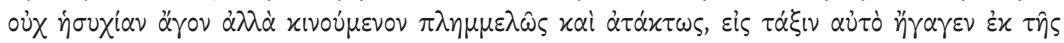

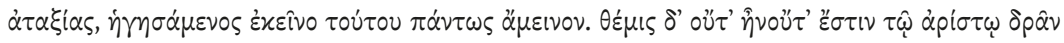

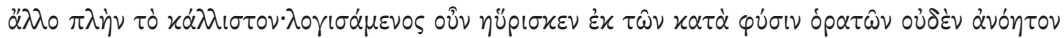

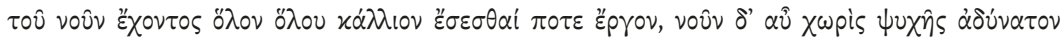

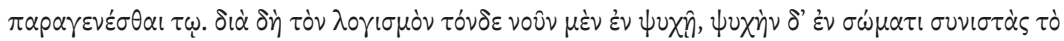

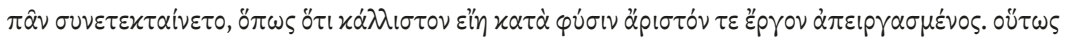

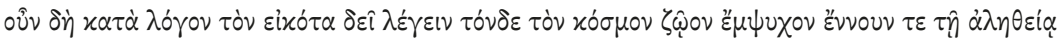

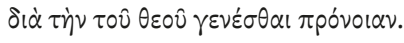

39 See e.g., $T i .37 \mathrm{c}$, and $53 \mathrm{a}-\mathrm{b}$.

40 See, for example, Fronterotta's (2003) translation: "E, una volta disposto tutto quanto, eglio tornò a permanere nella propria condizione abituale." Waterfield (2008) offers a similar translation: "With these arrangements in place, he resumed his life in his proper abode."

See Ti. 51b6-e6. 
crucial to remember that the god of the Timaeus may be wholly good but there is no evidence to suggest he is almighty. Thus, there is no reason to acknowledge an inconsistency, or jump to a metaphorical or counterfactual reading. The cosmos' punctual creation is explained by god's limited power, not by his goodness. Think about it in this way. If I want to give you a pot for your birthday - because that is the kind of thing you like-but it takes me a long time to master the technique, and even various failed attempts before I produce the final version, at no point do I love you any less because of my clumsy hands.

As can be seen, then, even if we take the cosmogony as a description of facts, the god is at no point lazy, envious, or inactive. He is just as good as he can be. ${ }^{42}$ Think about my son and his room again. Did he behave well today? Even if I am ignorant about the specifics of his behaviour during the day, I know he was playing in his room and that this is what normal children do. Then, when I asked him to tidy up his room, he complied. After that, content with what he had just done, he waited quietly to show me his ordered room, refraining from taking things out of their place again. It would be silly to say that before tidying up, or while he was waiting, he stopped behaving well.

\subsubsection{Traces of the Elements and Disorderly Motion in the Pre-cosmos}

The pre-cosmos has to be in movement because changeless existence is the prerogative of what always is, but then there is a question about the origin of that motion. It seems that if it is divine, it has to be ordered. Yet, the pre-cosmos is in huge disarray. So, what could be the source of these movements? The answer depends on whether souls are the origin of all motion or not. This is a highly contentious issue, given that the Timaeus is not completely clear in this respect. But in both cases, there are various possible solutions compatible with a factual reading of the cosmogony. Let me briefly explain why I prefer one of these alternatives over the others.

Vlastos (1964, 390-99) argues that Timaeus' cosmogony does not need to assume that the soul is the only source of movement. For him, the traces introduce a type of causation that does not depend on the soul. ${ }^{43}$ The traces may have an unmediated, but tenuous, causal relation with the Forms of the elements. ${ }^{44}$ How this relation is possible is, however, left unexplained. In contrast, Harte $(2010,133)$ suggests that the traces may not be the causal consequence

42 Although it went unnoticed, I think this is exactly what Vlastos $(1964,406)$ was trying to say.

43 See Ti. $5^{2 \mathrm{~d}} 4-53 a 3$ and $53 \mathrm{~b}$.

44 But see O'Meara's $\left(2017,5^{8-63}\right)$ argument against the idea that the traces are imitations of the Forms. 
of anything, but just a "brute fact that is left unexplained." 45 After all, even if all perceptible bodies must come into existence, traces may not be bodies (see Ti. 28b2-c2; 31b4-6). This, of course, might sound unsatisfactory. After all, by calling them "traces," the text invites us to reflect on how they could resemble the elements at all, and what ontological status they have. We are told they are powers, offer resistance, are causally active, have certain natures, and can be distinguished in terms of their kinds at some minimal level (see Timaeus $5^{2 \mathrm{~d} 2-}$ $53 \mathrm{~b} 7)$. So, if they are not bodies in the proper sense, they at least display some corporeal features. Thus, the traces may not be completely unexplainable; perhaps there is some way to explain them through the tenets explicitly endorsed in the dialogue. In any case, notice that these alternatives imply no inconsistency. They just acknowledge that the pre-cosmic traces lie at the explanatory limit of their interpretations (this, however, is not ideal, given EP2).

Consider now the idea that souls are the origin of all motion. This is suggested at Laws X, 892a1-b2:

ATHENIAN: It's the soul, my good friend, that nearly everybody seems to have misunderstood, not realizing its nature and power. Quite apart from the other points about it, people are particularly ignorant about its birth. It is one of the first creations, born long before all bodies, and is the chief cause of all their alterations and transformations. Now if that's true, anything closely related to soul will necessarily have been created before body, won't it, since soul itself is older than body?

CLINIAS: Necessarily. ${ }^{46}$

The passage, of course, is far from conclusive. Soul may be the cause of all motion inside the created cosmos where proper bodies exist. But if we accept the suggestion, it is still possible to argue for various interpretations. Perhaps the best-known option here is the one defended by Proclus - and more recently Clegg (1976) — who argues that the pre-cosmos as a whole has a non-rational,

45 See also Jelinek (2011).

46 Translated by Saunders in Cooper and Hutchinson (1997), with minor modifica-

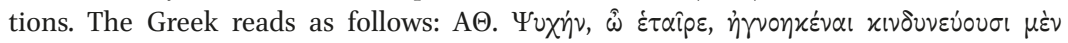

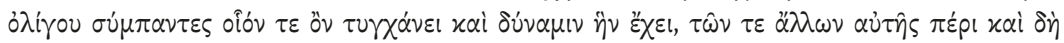

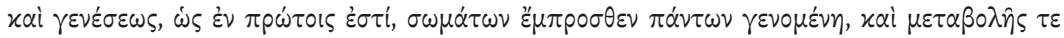

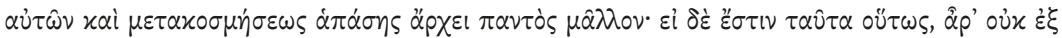

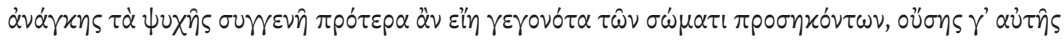

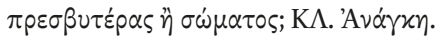


appetitive, evil soul. But this is not the only possibility. There is no reason to assume that the pre-cosmos as a whole has a strong unity. Perhaps, then, each trace has a non-rational soul. A problem remains, though-non-rational souls could explain the erratic movements of the traces, but it is difficult to see how they can explain the traces' resemblance to the elements.

Consider the Greek word used here for the traces: ichne (pl. of ichnos). A trace or footprint is the mark or residue left by something's or someone's actions. It is often the term used to refer to the footprints or signs left by divine action. The choice of words here suggests that the traces' movements and resemblance to Forms are caused not by non-rational souls, but by god's previous activity. ${ }^{47}$ The traces could be, for example, the remains of a previous cosmos the god destroyed to create a better one. In the Statesman's cosmological myth, for instance, the god causes huge chaos and natural disasters as collateral damage during his intervention to re-establish the immortality of the cosmos. ${ }^{48}$ Similarly, the god of the Timaeus might have needed a trial-anderror period to perfect his crafting skills. Of course, the decay of a previous cosmos may not have been due to god's direct activity but to that previous cosmos' limitations. The god's previous attempt might have crumbled unintentionally. If we go back to the pottery example, when I am practicing the skill, I might destroy a pot because I am unhappy with the results, or it could plummet from my fingers despite my best efforts (notice that I can use the clay again, and the clay might retain some properties of its previous shape).

This interpretation, however, raises a question about what happened before those previous attempts or divine actions, which is certainly left unexplained by the text. But notice that this is not the same as leaving passages of the text unexplained by the interpretation, and it certainly does not amount to an inconsistency. If I give you a recipe for bread pudding, one of the ingredients is pieces of stale bread, but I will not give you any instructions or explanations

47 Another reason to think that the traces do not move themselves is the hierarchy of motion at Ti. 89a1-5. There, Timaeus claims that "the best of the motions is one that occurs within oneself and is caused by oneself. This is the motion that bears the greatest kinship to understanding and to the motion of the universe. Motion that is caused by the agency of something else is less good. Worst of all is the motion that moves, part by part, a passive body in a state of rest, and does so by means of other things" ( $\tau \hat{\omega} \nu \delta^{\prime} \alpha \hat{v}$ $\iota v \eta \dot{\eta} \sigma \varepsilon \omega \nu$

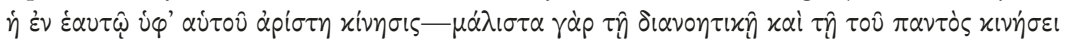

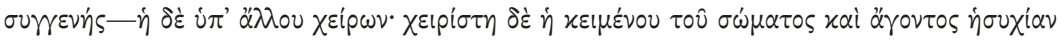

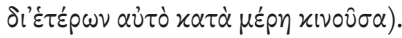

48 Sorabji $(1983,271)$ reminds us that Severus, a Middle Platonist from the second century CE, held a similar position. See ap. Procl. In Ti. (Diehl) 1.289, 7-13; 2.95, 29-96, 1. On the Statesman myth, see also chapter 1. 
about how to get those pieces of stale bread. My recipe assumes those ingredients, just as Timaeus' cosmogony presupposes the traces. Timaeus' task is to offer an account of the origin of the current cosmos only. Nothing in the Timaeus implies that the current cosmos is the only one that has ever existed, and if there were more, Timaeus is not obliged to give an account of the previous ones. ${ }^{49}$ Moreover, we can even conceive of this situation as laying the groundwork for further discussion on the matter (I have the Stoic reception of the Timaeus in mind here).

To sum up, we can describe the pre-cosmos as a non-temporal, incorporeal, and disordered stage of the chora and the powers in it. At the same time, and without implying any inconsistency, we can add that the pre-cosmic events happen in a sequence of events that presupposes relations of before, after, and simultaneity, the traces show certain corporeal features, and there is some basic but non-progressive order. Ontologically, traces in the chora have the most minimal degree of existence possible (even created elements rank very low on the scale, cf. Timaeus 49c7-5oa4). They sit at the antipodes of the created cosmos, which is as close to "what always is" as it could be. This should help us understand what Plato means by time, bodies (and individuation), and divine order.

\subsection{Conclusions}

Let me check whether I have delivered on my promises. Can my interpretation avoid the objections raised against previous attempts at reading the cosmogony as a factual and consistent account? The first complaint is that the type of reading I am proposing has no choice other than to posit a pre-cosmic time without sufficient textual evidence. However, as I have insisted, this is not true. There is no evidence to suggest that, in the Timaeus, a simple succession of events implies the presence of time. As I have shown, it is the other way around. The evidence suggests that in the dialogue, time presupposes the succession of events and the relations derived from it, but not vice versa. ${ }^{50}$ However, again and again, readers of Plato assume that succession of events implies time. But by doing this, they impose a (Newtonian) conception of time that is completely absent from the text.

49 See Ti. 29b1-2 and 31a-b. The text says there cannot be two simultaneous cosmoi but does not rule out a series of previous cosmoi.

50 This is one of the main differences between my interpretation and previous factual and literal readings (i.e., a2). 
The second objection against a consistent and factual reading of the cosmogony is that it is incompatible with the immutable relationship the god has with the world. However, as I have explained, once the activity of the god is properly specified, the proposal is compatible with the claim that god's activity is immutable. God is always good. If the god's relation to the world is to be good to it, then there is no inconsistency in saying that he did not create it until he was ready, then kept creating until there was nothing he could do to make it better. After that, the appropriate thing for him to do was to stop creating and refrain from destroying what he had made. Acting otherwise at any stage would change his good relationship with the cosmos.

A third objection is that this type of interpretation contradicts important Platonic doctrines found elsewhere. But as I reject a strong unitarian doctrinal reading of Plato, for me there is no serious problem with contradicting claims and arguments Plato offers in other texts (see $\mathrm{EP}_{4}$ and 5). Some souls in the Timaeus are generated. This is inconsistent with the Phaedrus, but consistent with the Laws (see Laws $x$, 892a1-b2).

Finally, you may ask whether I can explain why the world was created at that specific moment and not sooner or later. To this, one might answer that the god is not omnipotent, and all we need to know is that it created the cosmos at some point. It does not follow from the fact that we cannot determine when the cosmos started that there is no punctual beginning; humans would have no way of knowing. But the issue does not really depend on humans' cognitive limitations. The objection presupposes a pre-cosmic time, and since in my reading there is no such thing, the objection no longer makes sense. All we can say is that the cosmos began at the first moment of cosmic time, a punctual beginning established in relation to the pre-cosmic states that happen before and the ordered sequence afterwards.

Scholars have raised many more objections to the type of interpretation I am defending. I cannot possibly address every single one of them here. However, the exegetical principles proposed in section 4.3 block many of these objections. For example, metaphorical interpreters often resort to the authority of the Platonic tradition, even if it imposes a reading with insufficient textual evidence and forces a metaphorical reading (which go against $\mathrm{EP}_{3}$ and 4). Similarly, some objections only arise if one upholds a doctrinal reading of Plato, to the detriment of internal cohesion and explanatory power (which conflicts with E1 and E2).

I hope I have shown that reading the Timaeus in the way I am proposing is not impossible or mistaken but, on the contrary, close to the text, explanatory, and philosophically interesting. There is no need, then, to revert to interpretations that accept the inconsistency of the creation of time and risk turning 
a likely story into an impossible one. Moreover, the reading I propose is not rejected by the entire Platonic tradition. It is the type of reading that seems to have led the Stoics to their own cosmology and, on this issue, it is the interpretation championed by Plutarch in the Neoplatonic circle. Finally, if this reading is correct, it may mean that the rest of the Neoplatonic tradition was not reading Plato as closely as we would like to imagine, but this is compensated for by the fact that the powerful metaphysics derived from their metaphorical reading of the Timaeus belongs to their genius and not to Plato's. ${ }^{51}$

\section{References}

Anderson, G., and M. Bockmuehl, eds. 2018. Creation ex nihilo: Origins, Development, Contemporary Challenges. Notre Dame, Indiana: University of Notre Dame Press. doi:10.2307/j.ctvpg86fq.

Baltes, M. 1996. "ГÉrovev (Platon, Tim. 28 b 7). Ist die Welt real entstanden oder nicht?" In Polyhistor: Studies in the History and Historiography of Ancient Philosophy, edited by K. A. Algra, P. W. van der Horst, and D. T. Runia, 76-96. Leiden: Brill.

Betegh, G. 2010. "What Makes a Myth EIKO 2 ? Remarks Inspired by Myles Burnyeat's

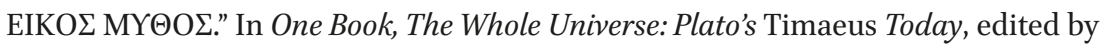
Richard D. Mohr and B. M. Sattler, 213-24. Las Vegas: Parmenides Publishing.

Brisson, L. 1998. Le même et l'autre dans la structure ontologique du Timée de Platon: Un commentaire systématique du Timée de Platon. Third edition. Sankt Augustin: Academia Verlag.

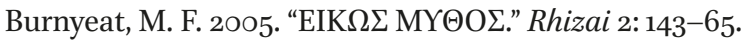

Carone, G. R. 2004. "Creation in the Timaeus: The Middle Way." Apeiron 37, no. 3: 211-26. Cherniss, H. 1944. Aristotle's Criticism of Plato and the Academy. 2 vols. Baltimore: Johns Hopkins University Press.

Clegg, J. S. 1976. "Plato's Vision of Chaos." The Classical Quarterly 26, no. 1: 52-61.

Cooper,J.M., andD.S.Hutchinson, eds.1997.Plato:CompleteWorks.Indianapolis:Hackett.

$5^{1}$ I wish to thank Viktor Ilievski, Silvia de Bianchi, Vasilis Politis, Francesco Fronterotta, Alberto Ross, the editors and anonymous reviewers for Brill's Plato Studies Series, the members of the Footnotes seminar, and audiences at the Autonomous University of Barcelona and Trinity College Dublin for their challenging questions and helpful feedback on previous drafts of this chapter. I am especially grateful to Gabriela Martínez Sainz for her support and patience. This research is part of PROTEus "Paradoxes and Metaphors of Time in Early Universe(s)", a project that has received funding from the European Research Council (ERC) under the Horizon 2020 research and innovation programme (Grant agreement No. 758145). 
Cornford, F. M. (1935) 1997. Plato's Cosmology: The Timaeus of Plato. London: Routledge. Reprint, Indianapolis: Hackett.

Dillon, J. 1997. "The Riddle of the Timaeus: Is Plato Sowing Clues?" In Studies in Plato and the Platonic Tradition, edited by M. Joyal, 25-42. Aldershot: Ashgate.

Erasmus J. 2018. The Doctrine of Creatio ex Nihilo. In: The Kaläm Cosmological Argument: A Reassessment. Springer, Cham. https://doi.org/10.1007/978-3-31973438-5_2.

Fronterotta, F., ed. 2003. Platone, Timeo. Milan: BUR.

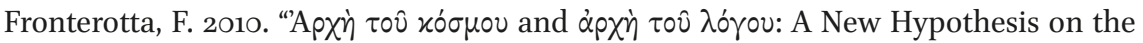
Beginning of the World in Plato's Timaeus." In Philosophy and Dialogue: Studies on Plato's Dialogues, edited by A. Bosch-Veciana and J. Monserrat-Molas, 141-55. Barcelona: Barcelonesa.

Gregory, A. 2008. "Introduction." In Plato: Timaeus and Critias, translated by R. Waterfield, ix-lvii. New York: Oxford University Press.

Guthrie, W. K. C. 1978. A History of Greek Philosophy, Vol. 5: The Later Plato and the Academy. Cambridge: Cambridge University Press.

Hackforth, R. 1959. "Plato's Cosmogony (Timaeus 27d ff.)." The Classical Quarterly 9, no. 1: $17-22$.

Harte, V. 2002. Plato on Parts and Wholes. Oxford: Clarendon Press.

Harte, V. 2010. "The Receptacle and the Primary Bodies: Something from Nothing?" In One Book, The Whole Universe: Plato's Timaeus Today, edited by R.D. Mohr and B. M. Sattler, 131-40. Las Vegas: Parmenides Publishing.

Jelinek, Elizabeth. 2011. Pre-Cosmic Necessity in Plato's Timaeus. Apeiron, 44, no. 3: $287-305$.

Johansen, T. K. 2004.Plato's NaturalPhilosophy. Cambridge:Cambridge University Press.

Mohr, Richard D. 1985. The Platonic Cosmology. Leiden: Brill.

Mohr, Richard D. 1986. "Plato on Time and Eternity." Ancient Philosophy 6: 39-46.

O'Meara, D. J. 2017. Cosmology and Politics in Plato's Later Works. Cambridge: Cambridge University Press.

Rashed, M., and T. Auffret. 2017. "On the Inauthenticity of the Critias." Phronesis 62, no. 3: 237-254.

Sedley, D. 2002. "The Origins of Stoic God." In Traditions of Theology, edited by D. Frede and A. Laks, 41-83. Leiden: Brill.

Sedley, D. 2007. Creationism and its Critics in Antiquity. Berkeley: The University of California Press.

Skemp,J. B. 1942. The Theory of Motion in Plato's Later Dialogues. Cambridge: Cambridge University Press.

Sorabji, R. 1983. Time, Creation and the Continuum. London: Duckworth.

Sorabji, R. 1988. Matter, Space, and Motion. London: Duckworth. 
Tarán, L. 1971. "The Creation Myth in Plato's Timaeus." In Essays in Ancient Greek Philosophy I, edited by J. P Anton and G. L. Kustas, 372-406. Albany: sunY Press.

Tarrant, H. 2019. "On Hastily Declaring Platonic Dialogues Spurious: The Case of Critias." Méthexis 31, no. 1: 47-66.

Taylor, A. E. 1928. A Commentary on Plato's Timaeus. Oxford: Clarendon Press.

Vlastos, G. 1939. “The Disorderly Motion in the Timaios.” The Classical Quarterly 33, no. 2: $71-83$.

Vlastos, G. 1964. "Creation in the Timaeus: Is it a Fiction?" In Studies in Plato's Metaphysics, edited by R. E. Allen, 401-19. London: Routledge.

Von Leyden, W. 1964. "Time, Number, and Eternity in Plato and Aristotle." The Philosophical Quarterly 14, no. 54: 35-52.

Waterfield, R., transl. 2008. Plato:Timaeus and Critias. NewYork: Oxford University Press. Zeyl, Donald J., ed. 20oo. Plato: Timaeus. Indianapolis: Hackett. 